\section{CASE REPORT}

doi: 10.5455/medarh.2016.70.392-394

Med Arch. 2016 Oct; 70(5): 392-394

Received: AUG 25, 2016 | Accepted: SEP 29, 2016

(c) 2016 Akin Firat Kocaay, Suleyman Utku Celik, Ilkin Hesimov, Tevfik Eker, Sibel Percinel and Seher Demirer

This is an Open Access article distributed under the terms of the Creative Commons Attribution Non-Commercial License (http://creativecommons.org/licenses/ by-nc/4.0/) which permits unrestricted non-commercial use, distribution, and reproduction in any medium, provided the original work is properly cited.

\title{
Adenoid Cystic Carcinoma of the Breast: A Clinical Case Report
}

\author{
Akin Firat Kocaay', Suleyman Utku Celik', Ilkin Hesimov', Tevfik \\ Eker $^{2}$, Sibel Percinel ${ }^{3}$, and Seher Demirer ${ }^{1}$

\begin{abstract}
'Department of General Surgery, Ankara University School of Medicine, Ankara, Turkey ${ }^{2}$ Department of General Surgery, Famagusta Medical Center Hospital, Gazimagusa, Turkish Republic of Northern Cyprus

${ }^{3}$ Department of Pathology, Ankara University School of Medicine, Ankara, Turkey
\end{abstract}

Corresponding author: Akin Firat Kocaay MD. Ankara University School of Medicine, Ibn-i Sina Hospital, 06100, Sihhiye, Ankara, Turkey, Mobile: +90 (0532) 20634 30. E-mail: firatkocaay@gmail.com

\begin{abstract}
Introduction: Adenoid cystic carcinoma (ACC) is an uncommon tumor of the breast, accounting for approximately $0.1 \%$ to $1 \%$ of all breast cancers. It is characterized by rare lymph node involvement and distant metastasis, and associated with a favorable prognosis with excellent survival, despite its triple-negative status. In the current state of knowledge, results of breast-conserving treatment with postoperative radiotherapy seem to be equivalent to mastectomy alone, with respect to survival for ACC of the breast. Due to its rarity, there is no consensus on optimal treatment for patients with ACC. Otherwise, the role of chemotherapy and hormonal therapy remains controversial. Further clinical studies are required to compare treatment options for ACC. But, a long-term follow-up is very important and mandatory for affected patients, due to the late onset of local relapse and occurrence of distant metastasis. Case report: Here, we report the case of a patient who presented with a palpable breast mass in the left breast that turned out to be an ACC of the breast.
\end{abstract}

Key words: adenoid cystic, breast, carcinoma, surgery, treatment.

\section{INTRODUCTION}

The salivary gland-like tumor of the breast also called adenoid cystic carcinoma (ACC) is a rare neoplasm that comprises less than $1 \%$ of all breast carcinomas (1). It has favorable prognosis, as lymph node involvement and distant metastasis are uncommon. ACC is characterized by a biphasic pattern and histologically, it consists of proliferating glands and stromal/basement membrane elements $(1,2)$. While common in salivary gland, this tumor also occurs at the other sites such as in the nasopharynx, trachea, uterine cervix, skin, lungs, and kidneys as well as the breast. The prognosis for ACC of the breast is better when compared to those in other locations.

ACC of the breast occurs between 30 and 90 years of age and more common in women in their fifth and sixth decade of life (2). It typically presents as a slow-growing mass, often in the subareolar area while some ACCs have been associated with breast tenderness and pain. Although radiological appearances are often nonspecific, the diagnosis can be made by fine-needle aspiration biopsy (3). ACC is generally negative for the estrogen (ER), progesterone (PR) receptors and HER-2/ neu (c-erbB2) $(2,3)$. In the present case, we report a patient with a diagnosis of ACC of the breast, and aim to present the treatment approach of this rare disease.

\section{CASE REPORT}

A fifty-one-year-old woman presented with a two months history of palpable mass in her left breast. Family history was negative for breast and ovarian cancer. Breast examination revealed a palpable mass about $5 \mathrm{~cm}$ in diameter in the lower inner quadrant of the left breast with no skin changes. Also, no palpable axillary lymphadenopathy was detected. 


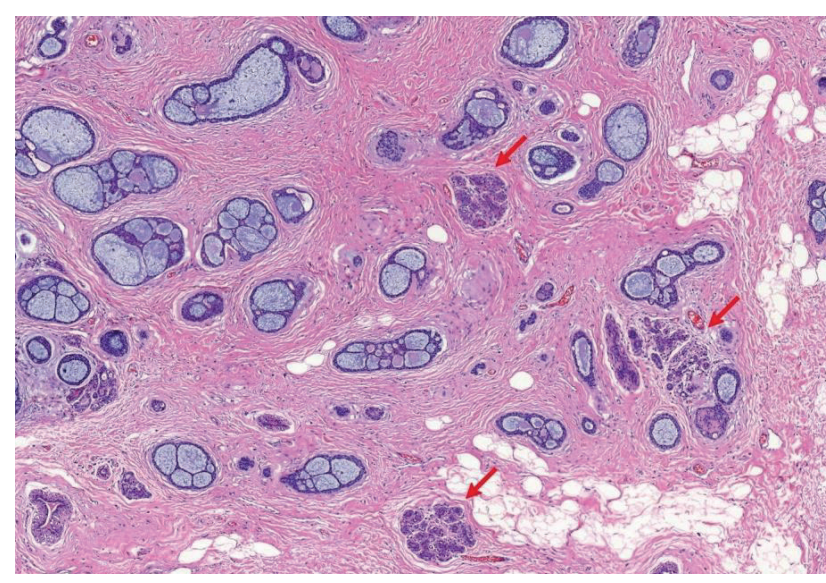

Figure 1. The cribriform pattern composed of cylindromatous microcystic spaces in which basophilic mucoid material was filled with (x5.7, HE; red arrows showing breast acini).

Ultrasonography revealed a lobulated, irregular, and hypoechoic mass and mammography demonstrated an asymmetric and non-homogenous hyperdense lesion. Pathological evaluation of the core biopsy specimen revealed invasive ductal carcinoma of the breast. Chest $\mathrm{X}$-ray, ultrasound of the abdomen, and bone scintigraphy were performed and there was no evidence of distant metastases. Then, a left modified radical mastectomy was performed. The histopathological examination revealed a $45 \mathrm{~mm}$ in the largest dimension consisted of cribriform, tubular and solid patterns. The cribriform pattern which was the dominant type in the tumor was
Incidence: $0.1 \%$ of all breast cancers

Age: 30-90 (most common in 5th and 6th decade)

Most common presentation: painful mass in the breast

Ultrasonography: hypoechoic solid lesion or heterogeneous

appearance

Mammography: benign-appearing, lobulated mass or irregular mass or asymmetric developing density

Axillary involvement: rare (0.8\% to $2 \%)$

Distant metastases: rare (most commonly in the lungs)

Hormone receptors: ER (-), PR (-), c-erb-B2 (-)

Surgical treatment:

Simple mastectomy

Lumpectomy + postoperative radiotherapy

Modified radical mastectomy

Radiotherapy: after breast-conserving surgery

\section{Chemotherapy: controversial}

Hormonotherapy: limited (triple negative in most cases)

Overall survival:

5 years: $88 \%$ to $98 \%$

10 years: $86 \%$ to $95 \%$

Table 1. Overview of adenoid cystic carcinoma of the breast.

of breast was first described by Geschickter in 1945 (2, 3 ). They are more commonly described in the salivary glands with aggressive characterization and poor prognosis. In contrast to the aggressive nature of the salivary gland tumors, ACC of the breast has an excellent prognosis (3).

The mean size of ACC is $3 \mathrm{~cm}$ (range, 1 to $12 \mathrm{~cm}$ ) (4, $5)$ and it rarely $(0.8 \%$ to $2 \%)$ causes axillary lymph node metastasis $(6,7)$. Nodal metastasis is rare and a routine

\begin{tabular}{|c|c|c|c|c|c|c|c|}
\hline Reference & $\begin{array}{l}\text { Number of } \\
\text { patients }\end{array}$ & $\begin{array}{l}\text { Conservative } \\
\text { treatment }\end{array}$ & $\begin{array}{l}\text { Follow-up duration } \\
\text { (months) }\end{array}$ & $\begin{array}{l}\text { Lymph node } \\
\text { involvement }\end{array}$ & $\begin{array}{l}\text { Distant } \\
\text { metas- } \\
\text { tasis }\end{array}$ & $\begin{array}{l}\text { ER/PR/Her2 sta- } \\
\text { tus (positivity, \%) }\end{array}$ & $\begin{array}{l}5 / 10 \text {-year over- } \\
\text { all survival (\%) }\end{array}$ \\
\hline Kulkarni et al (8) & 933 & $69.8 \%$ & 65.7 (median) & $5.1 \%$ & - & $15 / 13 /-$ & $88 /-$ \\
\hline Coates et al (9) & 376 & $60.3 \%$ & 62 (mean) & $6.1 \%$ & $1.1 \%$ & $12 / 10 /-$ & $94 / 86$ \\
\hline Ghabach et al (3) & 338 & - & - & $1.7 \%$ & $<1 \%$ & $10 / 8 /-$ & $98 / 95$ \\
\hline Thompson et al (10) & 244 & - & - & $4.9 \%$ & $2.9 \%$ & $-1-1-$ & $96 / 95$ \\
\hline Khanfir et al (7) & 61 & $67 \%$ & 79 (median) & $0 \%$ & $6.5 \%$ & $3 / 5 /-$ & $94 / 86$ \\
\hline
\end{tabular}

Table 2. A summary of five major study in the literature related to the clinical characteristics of ACC of the breast.

characterized by nests of cells with cylindromatous microcytic spaces in which basophilic mucoid material was filled with. The tubular pattern was made up of wellformed ducts and tubules with central lumina lined by inner epithelial and outer myoepithelial cells. In the solid areas, sheets of uniform basaloid cells lacking tubular or microcytic formation were observed (Figure 1). Seven mitoses were counted in ten high power fields. Moreover, axillary lymph nodes were negative for metastases and the neoplastic cells were negative for ER expression and HER-2/neu but positive for PR (70\%). On the basis of the morphological findings, the tumor was diagnosed as breast salivary gland type carcinoma, adenoid cystic carcinoma. After the operation, the patient's treatment was continued with adjuvant chemotherapy and hormonal therapy. No loco-regional recurrence or distant metastasis was found at the 32-month follow-up.

\section{DISCUSSION}

Adenoid cystic carcinoma (ACC) of the breast was first termed "cylindroma" by Billroth in 1856 and ACC axillary dissection is not recommended in this special type of cancer $(5,6)$. Distant metastases are uncommon and can occur without positive axillary nodes. Metastases are most commonly in the lung but also have been reported in liver, kidney, and bone $(2,8)$. Metastases may be seen many years after the initial diagnosis and prolonged survival rates are reported in several series (Table 1).

There is no consensus on optimal treatment for ACC of the breast because of its rarity. Surgical management options for treatment include lumpectomy, wide excision with or without radical radiation, or modified radical mastectomy (5-7). Local recurrence rates after lumpectomy or local excision are not rare and varying from $6 \%$ to $37 \%$, more so in patients not receiving adjuvant radiotherapy $(1,5,7)$. But adjuvant radiotherapy after local excision or lumpectomy decreases the local recurrence rates (6). Modified radical mastectomy is the most reported surgical procedures for ACC of the breast, simply because it used to be the standard treatment for common breast cancers (5). However, results 
of breast-conserving treatment that includes adjuvant radiotherapy seem to be equivalent to those of mastectomy alone, with respect to survival $(5,9)$. Mastectomy is recommended for invasive lesions when a cosmetically satisfactory excision is not possible, especially when the tumor has a high-grade pattern (6).

In contrast to other triple-negative breast carcinomas, ACCs have a relatively good prognosis and they are usually low-grade (3-5). In present case, the patient's receptors status was followed as: ER-negative, PR-positive (70\%), and HER-2/neu-negative. The modified radical mastectomy was performed which showed no axillary node involvement. The patient was not given radiotherapy; however, chemotherapy and hormonotherapy (tamoxifen) were administered postoperatively.

As shown Table 2, after definitive treatment, the 10year overall survival rate is $86 \%$ to $95 \%$, and lymph node metastasis is very rare, as well as distant metastases (3, 7-10). Data from the published literature indicate that ACCs of the breast have a very good prognosis after achieving local control, and the overall survival is not significantly different from the general population. These findings suggest that patients with ACC would derive little if any improvement in survival from adjuvant systemic therapy and thus can be spared the side effects and the cost of such therapy $(1,6)$.

\section{CONCLUSION}

With the information available today, the treatment of ACC of the breast is seen as to be mastectomy and addition of axillary lymph node dissection in patients with positive sentinel lymph nodes or breast-conserving treatment that includes adjuvant radiotherapy. Routine axillary lymph node dissection is not recommended due to the fact that the metastasis is less than $2 \%$. Because of the excellent prognosis with ACC, the benefit to survival from systemic therapy is negligible. Due to the late onset of local relapse, as well as distant metastasis, a long-term follow-up is very important and mandatory for these patients. Further clinical investigations comparing treatment options for ACC are inevitable to define the optimal treatment.

- Informed Consent: Written informed consent was signed by the patient and responsible physician.
- Conflicts of Interest: The authors have no conflict of interests to disclose.

- Authorship: All authors had access to the relevant data and a role in writing the manuscript.

- Funding: The authors have no funding sources related to this publication.

\section{REFERENCES}

1. Millar BA, Kerba M, Youngson B, Lockwood GA, Liu FF. The potential role of breast conservation surgery and adjuvant breast radiation for adenoid cystic carcinoma of the breast. Breast Cancer Res Treat. 2004; 87(3): 225-32.

2. Canyilmaz E, Uslu GH, Memış Y, Bahat Z, Yildiz K, Yoney A. Adenoid cystic carsinoma of the breast: A case report and literature review. Oncol Lett. 2014; 7(5): 1599-1601.

3. Ghabach B, Anderson WF, Curtis RE, Huycke MM, Lavigne JA, Dores GM. Adenoid cystic carcinoma of the breast in the United States (1977 to 2006): a population-based cohort study. Breast Cancer Res. 2010; 12(4): R54.

4. Miyai K, Schwartz MR, Divatia MK, Anton RC, Park YW, Ayala AG, et al. Adenoid cystic carcinoma of breast: Recent advances. World J Clin Cases. 2014; 2(12): 732-41.

5. Boujelbene N, Khabir A, Boujelbene N, Jeanneret Sozzi W, Mirimanoff RO, Khanfir K. Clinical review - breast adenoid cystic carcinoma. Breast. 2012; 21(2): 124-7.

6. Arpino G, Clark GM, Mohsin S, Bardou VJ, Elledge RM. Adenoid cystic carcinoma of the breast. Moleculer markers, treatment, and clinical outcome. Cancer. 2002; 94(8): 2119-27.

7. Khanfir K, Kallel A, Villette S, Belkacémi Y, Vautravers C, Nguyen T, et al. Management of adenoid cystic carcinoma of the breast: a Rare Cancer Network study. Int J Radiat Oncol Biol Phys. 2012; 82(5): 2118-24.

8. Kulkarni N, Pezzi CM, Greif JM, Suzanne Klimberg V, Bailey L, Korourian S, et al. Rare breast cancer: 933 adenoid cystic carcinomas from the National Cancer Data Base. Ann Surg Oncol. 2013; 20(7): 2236-41.

9. Coates JM, Martinez SR, Bold RJ, Chen SL. Adjuvant radiation therapy is associated with improved survival for adenoid cystic carcinoma of the breast. J Surg Oncol. 2010; 102(4): 342-7.

10. Thompson K, Grabowski J, Saltzstein SL, Sadler GR, Blair SL. Adenoid cystic breast carcinoma: is axillary staging necessary in all cases? Results from the California Cancer Registry. Breast J. 2011; 17(5): 485-9. 